\title{
Human Alveolar Macrophage-derived Chemotactic Factor for Neutrophils
}

\author{
STIMULI AND PARTIAL CHARACTERIZATION
}

\author{
Gary W. Hunninghake, James E. Gadek, Henry M. Fales, and Ronald G. Crystal, \\ Pulmonary Branch and Laboratory of Chemistry, National Heart, Lung and \\ Blood Institute, National Institutes of Health, Bethesda, Maryland 20205
}

A B S T R A C T The presence of neutrophils within the lung is a characteristic feature of a variety of lung diseases. To evaluate the potential role of alveolar macrophages in modulating the migration of neutrophils to the lung, normal human alveolar macrophages obtained from volunteers by bronchopulmonary lavage, were exposed for various periods of time in vitro to heat-killed microorganisms, and noninfectious particulates, immune complexes, and the macrophage supernates were evaluated for chemotactic activity. The microorganisms, noninfectious particulates, and immune complexes were chosen as stimuli for alveolar macrophages because these stimuli are representative of a spectrum of pathogenic agents that cause neutrophil accumulation in the lower respiratory tract. After incubation with each of these stimuli, alveolar macrophages released low molecular weight (400-600) chemotactic factor(s) (alveolar macrophage-derived chemotactic factor[s] [AMCF]) with relatively more activity for neutrophils than monocytes or eosinophils. Checkerboard analysis of the AMCF revealed that the factor was primarily chemotactic and not chemokinetic for neutrophils. The selectivity for neutrophils vs. monocytes could not be explained by a selective deactivation of monocytes, because the AMCF was more potent in deactivating neutrophils than monocytes. Partial characterization of AMCF demonstrated it was heterogeneous with the following features: $(a)$ stable to heating at 56 and $100^{\circ} \mathrm{C}$ for $30 \mathrm{~min}$; (b) stable over a $\mathrm{pH}$ range of 1.0 to 12.0 for $60 \mathrm{~min}$; (c) stable after exposure to trypsin, papain, chymotrypsin, collagenase, and elastase; $(d)$ partially inhibited by serum chemotactic factor inhibitor(s); (e) two major isoelectric points

This paper was presented in part at the National Meeting of the American Federation for Clinical Research, San Francisco, Calif., May 1978.

Received for publication 13 September 1978 and in revised form 30 April 1980.
(pI 7.6 and 5.2); and $(f)$ partially extractable into ethyl acetate, ether, and hexane. Although AMCF was, at least, partially lipid in nature, it did not appear to be similar to previously described lipid chemotactic factors (e.g., hydroxy-derivatives of 5,8,10,14-eicosatetraenoic acid); analysis by gas chromatography-mass spectrophotometry of AMCF extracted into ethyl acetate did not reveal the presence of 5,8,10,14-eicosatetraenoic acid. The macrophage supernates containing the AMCF also stimulated normal human neutrophils to release lysozyme and lactoferrin but not lactate dehydrogenase. These studies suggest that a wide variety of potentially pathogenic stimuli induce normal alveolar macrophages to generate a low molecular weight chemotactic factor(s) that preferentially attracts neutrophils. Because alveolar macrophages are normal residents of alveoli, it is likely that by releasing this factor(s) macrophages play a significant role in amplifying the inflammatory processes seen in many acute and chronic lung diseases.

\section{INTRODUCTION}

It has been well documented that an important function of the alveolar macrophage is to preserve the integrity of the lower respiratory tract by ingesting and eliminating pathogenic agents $(1,2)$. Recent studies in animal models have suggested that the macrophage can amplify its role in defending the lower respiratory tract by secreting chemotactic factor(s) that recruit other types of inflammatory and immune effector cells, particularly neutrophils, to the alveolar structures $(3,4)$. Such alveolar macrophage-derived chemotactic factor(s) (AMCF) ${ }^{1}$ may have particular im-

\footnotetext{
${ }^{1}$ Abbreviations used in this paper: AMCF, alveolar macrophage-derived chemotactic factors; BSA, bovine serum albumin; ECF-A, extracellular fluid; GS-MS, gas chromatography-mass spectrophotometry; HBSS, Hanks' balanced
} 
portance in the human lung, not only because of its role in lung defense, but also because the production of AMCF may help explain the accumulation of neutrophils in alveolar structures in association with a variety of pathologic insults.

If the release of such chemotactic factor(s) for neutrophils does play an important role in human disease, their production should be associated with the interaction of the alveolar macrophage with those pathogenic agents known to cause neutrophil accumulation in the lower respiratory tract (5-14). Since neutrophils appear in the lung within hours of a pathologic insult, it would be expected that AMCF would be released rapidly following interaction of the macrophage with a potentially injurious agent. In addition, because neutrophils are rarely found in the alveolar structures of normal lung, it is unlikely that the resting, unstimulated alveolar macrophage would release AMCF.

To evaluate the potential role of the alveolar macrophage in modulation of neutrophil migration to the lung in various disease states, we have examined the capacity of various pathogenic agents to stimulate normal human alveolar macrophages to generate and release chemotactic factor(s) for neutrophils. This was accomplished by obtaining alveolar macrophages from normal volunteers by bronchoalveolar lavage, culturing the macrophages with different classes of potentially pathogenic stimuli, and testing the macrophage supernates for neutrophil chemotactic activity.

\section{METHODS}

Preparation of blood leukocytes. Mononuclear cells and neutrophils were obtained from peripheral blood of normal volunteers by sedimentation in pyrogen-free Plasmagel (HTI Corp., Buffalo, N. Y.) followed by Hypaque-Ficoll centrifugation (15). The resulting mononuclear cell suspensions contained $>98 \%$ mononuclear cells of which $\sim 80 \%$ were lymphocytes and $20 \%$ were monocytes, while the polymorphonuclear leukocytes (PMN) suspensions contained $>98 \%$ neutrophils. In those studies designed to evaluate the relative selectivity of the macrophage chemotactic factor for neutrophils compared with eosinophils, PMN suspensions were also obtained from three individuals with peripheral blood eosinophilia and allergic rhinitis secondary to a documented ragweed allergy. PMN suspensions from these three individuals contained $8-20 \%$ eosinophils and 80-92\% neutrophils.

Bronchoalveolar lavage. Bronchoalveolar lavage was performed on six nonsmoking, healthy volunteers (mean age $21 \pm 1 \mathrm{yr})$ as previously described $(7,13,14)$. The cells were separated from lavage fluid by centrifugation, washed three times, and then evaluated for total number, viability, and differential count (14). (All data are presented as mean \pm SEM).

Preparation of alveolar macrophages. In the six volunteers the average lavage fluid cell differential of these indi-

salt solution; HETE, 5,8,10,14-eicosatetraenoic acid; LDH, lactic acid dehydrogenase; ORBC, ox erythrocytes; PBS, phosphate-buffered saline; PMN, polymorphonuclear leukocytes; SRBC, sheep erythrocytes. viduals included: $92 \pm 1 \%$ alveolar macrophages, $7 \pm 1 \%$ lymphocytes, and $1 \pm 1 \%$ neutrophils; eosinophils, basophils, and mast cells were not found. Viable mononuclear cells were further purified from the recovered cells by HypaqueFicoll density centrifugation; the resulting mononuclear cell suspensions were $>98 \%$ viable and contained, on the average, 93\% macrophages and 7\% lymphocytes. These cell suspensions (referred to subsequently as "macrophages") were then adjusted to a concentration of $10^{7} / \mathrm{ml}$ in RPMI-1640 (Microbiological Associates, Walkersville, Md.) and were used to generate the macrophage supernates, as described below.

Classes of materials used to stimulate alveolar macrophages. Three classes of materials were used to stimulate the alveolar macrophages obtained by bronchoalveolar lavage: (a) microorganisms; (b) noninfectious particulates; and $(c)$ immune complexes.

Because some living microorganisms produce chemotactic factors $(16,17)$, the microorganisms used in this study were heat-killed before use. Heat-killed Staphylococcus albus (National Institutes of Health microbiological service) was used as an example of a bacterial stimulus and zymosan (yeast cell walls) particles (Sigma Chemical Co., St. Louis, Mo.) were used as an example of a nonbacterial, particulate infectious agent. The $S$. albus were adjusted to a concentration of $5 \times 10^{8}$ organisms $/ \mathrm{ml}$ in RPMI-1640. The zymosan particles were prepared as described by Fine et al. (18), washed three times in Hanks' balanced salt solution (HBSS), and resuspended in RPMI-1640 to a concentration of $1 \mathrm{mg} / \mathrm{ml}$.

As an example of a noninfectious particulate, Sepharose-4B particles (Pharmacia Fine Chemicals, Div. of Pharmacia, Inc., Piscataway, N. J.) were used after washing the particles three times in HBSS and resuspending them in RPMI-1640 at a concentration of $10 \%$ by volume.

To evaluate the potential influence of opsonization on the ability of the microorganisms or Sepharose-4B to act as stimuli for the alveolar macrophages, the heat-killed S. albus, zymosan, and Sepharose-4B were opsonized by incubation in fresh normal human serum for $1 \mathrm{~h}$ at $37^{\circ} \mathrm{C}$ followed by three washings in RPMI-1640 and final suspension in RPMI-1640 at the concentrations described above.

Both soluble and particulate immune complexes were used as examples of immune complex stimuli. Soluble antigenantibody complexes were prepared from bovine serum albumin (BSA) and immunoglobulin (Ig)G anti-BSA antibody raised in rabbits. Antigen-antibody complexes were prepared at five times antigen-excess in RPMI-1640 and represented a total protein concentration of $1 \mathrm{mg} / \mathrm{ml}$.

Three different particulate immune complexes were used as potential stimuli: (a) ox erythrocytes (ORBC) coated with just subagglutinating amounts of rabbit IgG anti-ORBC antibody (7S EA; N. L. Cappel Laboratories, Inc., Cochranville, Pa.) and suspended in RPMI-1640 at a concentration of $5 \times 10^{8} \mathrm{cells} / \mathrm{ml} ;(b)$ ORBC coated with just subagglutinating amounts of rabbit IgM anti-ORBC antibody (19S EA; Cappel Laboratories, Inc.) and suspended in RPMI-1640 at a concentration of $5 \times 10^{8}$ cells $/ \mathrm{ml}$; and $(c)$ sheep erythrocytes (SRBC) coated with subagglutinating amounts of rabbit IgM anti-SRBC antibody and mouse complement (EAC) and suspended in RPMI-1640 at $5 \times 10^{8}$ cells $/ \mathrm{ml}$.

Incubation of alveolar macrophages with various stimuli. To evaluate the production of chemotactic activity by alveolar macrophages, the macrophages were incubated in sterile tissue culture plates (24 wells/plate, $16 \mathrm{~mm}$ well Diam; Costar, Data Packaging, Cambridge, Mass.) at $37^{\circ} \mathrm{C}$ in $5 \% \mathrm{CO}_{2}$ in air at $100 \%$ humidity on a rocker platform (Bellco Glass, Inc., Vineland, N. J.) ( 7 cycles/min) for various periods of time, either alone or in the presence of one of the several stimuli described above. The macrophage cultures were prepared by 
mixing $0.8 \mathrm{ml}$ of RPMI-1640, $0.1 \mathrm{ml}$ of the alveolar macrophage suspension, and $0.1 \mathrm{ml}$ of the various stimuli in wells of the tissue culture plates. At various times $(0,0.5,1,2,3,4$, and $18 \mathrm{~h}$ ) after initiation of the cultures, the macrophage supernates were harvested by aspiration and filtered through 0.45 $\mu \mathrm{m}$ filters (Swinnex-13, Millipore Corp., Bedford, Mass.) to remove cells and the particulate stimuli. Control preparations for these experiments included supernates from alveolar macrophages alone and supernates from each of the stimuli alone. All supernates were stored at $-20^{\circ} \mathrm{C}$ and were assayed within 2 wk of harvesting.

Evaluation of alveolar macrophage supernates for chemotactic activity. To evaluate the alveolar macrophage supernates for chemotactic activity directed toward neutrophils or mononuclear cells, a blindwell micropore filter chamber technique was used with nucleopore filters $(3-\mu \mathrm{m}$ pore size for polymorphonuclear leucocytes, $5-\mu \mathrm{m}$ pore size for mononuclear cells; Neuro Probe, Inc., Bethesda, Md.), as previously described (19).

To insure that the migration of neutrophils across the membrane in response to the macrophage supernates was due to directed migration (chemotaxis) and not merely increased random migration (chemokinesis) (20), in some experiments, varying amounts of the chemotactic stimulus were added to both the upper and lower compartments of the chamber.

To validate the results of these assays, chemotaxis was also evaluated using Sartorius filters (Sartorius AG, Göttingen, West Germany) in a leading front assay as previously described (4) and a chemotaxis under agarose assay (21). The results obtained using the various chemotactic assays were comparable.

In order to compare the relative capacity of AMCF to deactivate neutrophils vs. mononuclear cells, neutrophil and mononuclear cell suspensions were incubated with varying amounts of AMCF before their use in the chemotaxis assay. After incubation with AMCF at $37^{\circ} \mathrm{C}$ for $15 \mathrm{~min}$, the cells were washed three times and placed in the upper compartment (cell) of the chemotaxis chamber. Into the lower compartment (stimulus) of the chamber was added $150 \mu$ l of either media alone (RPMI-1640), AMCF, $N$-formyl-Met-Leu-Phe (50 nM; Peninsula Laboratories, Inc., San Carlos, Calif.) or $5 \%$ endotoxin-activated serum (22). The migration of both neutrophils and mononuclear cells across the nucleopore filter in response to each of these stimuli was then evaluated as described above.

To compare the relative chemotactic activity of the macrophage supernates for neutrophils vs. eosinophils, PMN suspensions containing both neutrophils and eosinophils were prepared as described above. For these experiments, a chemotaxis-under-agarose assay (21) was used, in addition to the nucleopore filter assay.

Partial characterization of AMCF. Molecular sieve chromatography of the alveolar macrophage supernates was performed on a $2.5 \times 100-\mathrm{cm}$ column of Sephadex G-25 (Pharmacia Fine Chemicals) and a $1.5 \times 90-\mathrm{cm}$ column of BioGel P-2 (Bio-Rad Laboratories, Richmond, Calif.). The columns were packed and eluted with $0.85 \% \mathrm{NaCl}-40 \mathrm{mM}$ phosphate, pH 7.4 phosphate-buffered saline (PBS) at $4^{\circ} \mathrm{C}$. $3-\mathrm{ml}$ fractions were collected and assayed directly for chemotactic activity using the nucleopore filter assay. The G-25 Sephadex column was calibrated with cytochrome $C(12,500 \mathrm{~mol} \mathrm{wt})$, bacitracin $(1,450 \mathrm{~mol} \mathrm{wt})$ and $\left[{ }^{3} \mathrm{H}\right]$ thymidine $(242 \mathrm{~mol} \mathrm{wt})$. The Bio-Gel P-2 column was calibrated with vitamin $B_{12}(1,350 \mathrm{~mol}$ wt) and $\left[{ }^{3} \mathrm{H}\right]$ thymidine.

Isoelectric focusing of AMCF was performed in a horizontal bed of granulated gel (Ultrodex; LKB Instruments, Inc. Rockville, Md.). A pH gradient of 2.5-9 was established using a composite of ampholytes (Bio-Rad Laboratories) at a final concentration of $2 \%(w t / w t)$ in the gel slurry (23). AMCF partially purified by prior gel filtration was added to the granulated gel bed $(3 \% \mathrm{vol} / \mathrm{vol})$ before applications of electrofocusing current. Isoelectric focusing was carried out at $25 \mathrm{~W}$, $5^{\circ} \mathrm{C}$, for $16 \mathrm{~h}$. The gel was then collected as $75-\mathrm{mm}$ strips proceeding from anode to cathode. The pH of each step was determined and then eluted with $3 \mathrm{ml}$ of PBS. The eluate from the gel strips was then assayed for neutrophil chemotactic activity as described above. Control isoelectric focusing was performed on alveolar macrophage supernates containing no chemotactic activity. Analysis of control runs demonstrated that the granulated gel-ampholyte focusing bed itself did not contain measurable chemotactic activity for neutrophils.

The heat stability of the AMCF was evaluated by heating the macrophage supernates for $30 \mathrm{~min}$ at 56 and $100^{\circ} \mathrm{C}$. The sensitivity of AMCF to trypsin, chymotrypsin, papain, clostridial collagenase, and pancreatic elastase was evaluated by incubating the AMCF with each enzyme at a final concentration of $10 \mu \mathrm{g} / \mathrm{ml}$ for $30 \mathrm{~min}$ at $37^{\circ} \mathrm{C}$. The papain, trypsin, and chymotrypsin were obtained from Sigma Chemical Corp., the elastase and collagenase were obtained from Worthington Biochemical Corp., Freehold, N. J. After this incubation, the enzymes were inactivated by heating for $15 \mathrm{~min}$ at $100^{\circ} \mathrm{C}$.

The pH stability of the AMCF was evaluated by adjusting the $\mathrm{pH}$ of the supernates containing the AMCF to 1.0, 3.5, $7.4,9.0$, and 12.0 with $1 \mathrm{~N} \mathrm{HCl}$ or $\mathrm{NaOH}$. After $1 \mathrm{~h}$ of incubation, the $\mathrm{pH}$ of the supernates was readjusted to 7.4.

The solubility of AMCF in organic solvents was evaluated by extracting $5 \mathrm{ml}$ of the macrophage supernates containing AMCF twice with equal volumes of ethyl acetate, ether, or hexane. Extraction into ethyl acetate was tested with the macrophage supernates adjusted to $\mathrm{pH} 3.5,7.4$, or 12.0 ; the ether and hexane extractions were performed with the macrophage supernate at $\mathrm{pH}$ 7.4. After each extraction, the organic solvents were dried with a stream of $\mathrm{N}_{2}$ and the extracted material resuspended in $5 \mathrm{ml}$ of RPMI-1640. This material, as well as the remaining aqueous phages, were then tested for chemotaxis for neutrophils as described above. Before testing, $\mathrm{N}_{2}$ was bubbled through the aqueous phases to remove any residual organic solvent; the aqueous phases extracted with ethyl acetate were readjusted to $\mathrm{pH}$ 7.4. In all cases, $>90 \%$ of the AMCF activity in the original macrophage supernates was recovered in the organic plus aqueous phases.

To determine whether supernates of the stimulated macrophages contained hydroxyl-derivatives of $5,8,10,14$ eicosatetraenoic acid (HETE) (24), AMCF present in $100 \mathrm{ml}$ of a supernate of $10^{8}$ stimulated alveolar macrophages was extracted into ethyl acetate and evaporated to a volume of $200 \mu \mathrm{l}$ with a stream of $\mathrm{N}_{2}$ as described above. The supernates were then analyzed for the presence of HETE by gas chromatography-mass spectrophotometry (GC-MS) in the same manner as described by Hamberg and Samuelsson (25). Briefly, the extract was first treated with an excess of ethereal diazomethane and then, after evaporation of the solvents, the residue was silylated using an excess $(200 \mu \mathrm{l})$ of bistrimethylsilyltrifluoroacetamide. A $2-\mu$ l aliquot of this solution ( $1 \%$ of the total volume) was subjected to GC-MS analysis using a $3 \%$ OV-17 column programmed at $1^{\circ} \mathrm{C} / \mathrm{min}$, with an LKB-9000 combined GC-MS spectrometer.

The effect of a serum-derived chemotactic factor inhibitor on AMCF was tested by preparing the chemotactic factor inhibitor from normal human serum as described by Berenberg and Ward (26). The chemotactic factor inhibitor (0.1) was mixed with macrophage supernate $(0.4 \mathrm{ml})$, incubated at $23^{\circ} \mathrm{C}$ for $30 \mathrm{~min}$, and then tested for chemotactic activity in the nucleopore filter assay.

Effect of AMCF on neutrophils. In addition to inducing 
neutrophils to follow a path of directed migration, the ability of AMCF to induce neutrophils to release a variety of products was evaluated. Three neutrophil products were evaluated $(27,28)$; lysozyme, $\beta$-glucuronidase, and lactoferrin. For comparison, the release of lactic acid dehydrogenase (LDH), a cytoplasmic marker, was also determined.

To evaluate the influence of AMCF on these neutrophil products, $1-5 \times 10^{7}$ neutrophils $(900 \mu \mathrm{l}$ in HBSS) were placed in $12 \times 75-\mathrm{mm}$ plastic tubes containing a $3-\mu \mathrm{m}$ chemotactic filter in the bottom of the tube (29). Supernates $(100 \mu \mathrm{l})$ from macrophages stimulated with Sepharose-4B were then added (yielding a final dilution of the macrophage supernate of $1: 10$ ), and the cells were incubated at $37^{\circ} \mathrm{C}$ for $0,30,60$, or $120 \mathrm{~min}$. Supernates of the neutrophil cultures were then harvested by passing the culture contents through $0.45-\mu \mathrm{m}$ filters to remove the cells. As controls, supernates from unstimulated macrophages were incubated with the neutrophils as was media alone. The supernates from the stimulated macrophages were evaluated for lysozyme, $\beta$-glucuronidase, lactoferrin, and LDH.

Lysozyme activity was determined by measuring the rate of change of turbidity of a solution of Micrococcus lysodeikticus (Worthington Biochemical Corp.) at $\mathrm{pH} 6.2$ (30). $\beta$-Glucuronidase was assayed by measuring the release of phenolphthalein from $\beta$-glucuronate (Sigma Chemical Co.) after $6 \mathrm{~h}$ of incubation at $\mathrm{pH} 4.5$ (31). Lactoferrin was quantitated by radial immunodiffusion in agarose gels using rabbit antisera to human lactoferrin and purified human colostral lactoferrin (Calbiochem-Behring Corp., American Hoechst Corp., San Diego, Calif.) as a standard (32). LDH activity was determined by measuring the rate of decrease of absorbance at $340 \mathrm{~mm}$ resulting from the oxidation of NADH during conversion of pyruvate to lactate (33).

All statistical comparisons made using the two-tailed $t$ test.

\section{RESULTS}

Ability of microorganisms and noninfectious particulates to stimulate alveolar macrophages to release $A M C F$. Supernates of normal human alveolar macrophages maintained in culture for $3 \mathrm{~h}$ did not contain chemotactic activity for neutrophils. In contrast, when these macrophages were cultured with heat-killed microorganisms (S. albus, zymosan) or noninfectious particulates (Sepharose-4B), supernates of these cells contained chemotactic activity for normal human neutrophils (Fig. 1).

Prior opsonization of each of the particles with fresh human serum significantly increased their ability to stimulate the release of the chemotactic factor from alveolar macrophages (Fig. 1; $P<0.01$, all comparisons). Opsonization of the particles not only increased the amount of chemotactic factor released by stimulated macrophages but also increased the rate of release of the factor from the cells (data not shown). This increased chemotactic activity was clearly generated by the macrophages, because none of the opsonized particles alone (cultured without macrophages) possessed chemotactic activity.

Unstimulated macrophages maintained in culture for 0-4 $\mathrm{h}$ did not produce the chemotactic factor (Fig. 2). In comparison, macrophages presented with

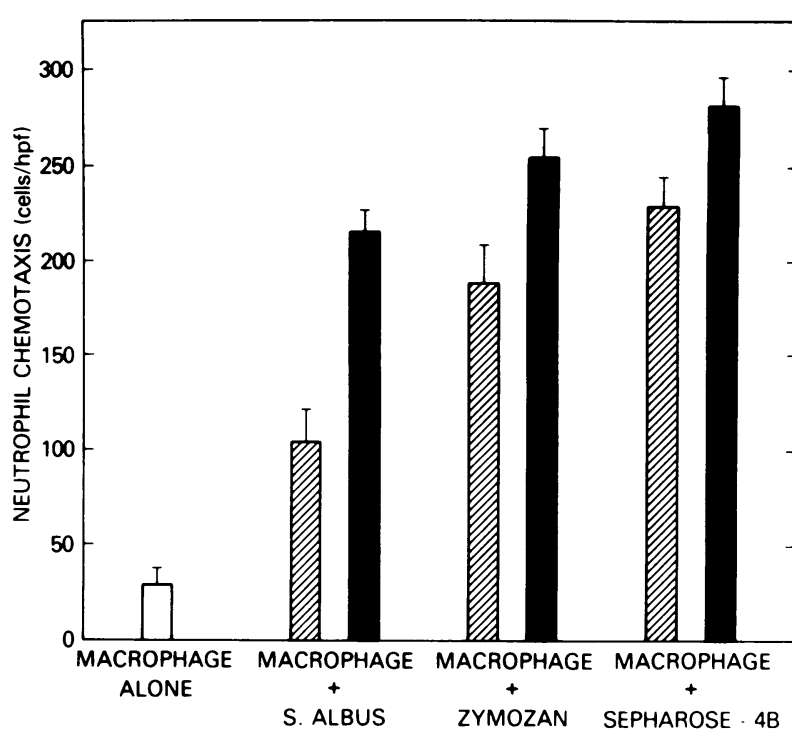

FIGURE 1 Neutrophil chemotactic activity in supernates of control alveolar macrophages $(\square)$ compared with macrophages stimulated in vitro for $3 \mathrm{~h}$ by opsonized $(\square)$ or nonopsonized (घ) S. albus, zymosan, or Sepharose-4B. Neutrophil chemotaxis is expressed as the number of cells per high power field (hpf) reaching the lower surface of a micropore filter. The data represent the mean $\pm \mathrm{SEM}$ of three separate experiments.

opsonized S. albus generated significant amounts of the chemotactic factor after $2 \mathrm{~h}$ of culture, with maximal production being reached in $3 \mathrm{~h}$. Interestingly, after 18 $h$ of culture, supernates from the unstimulated macro-

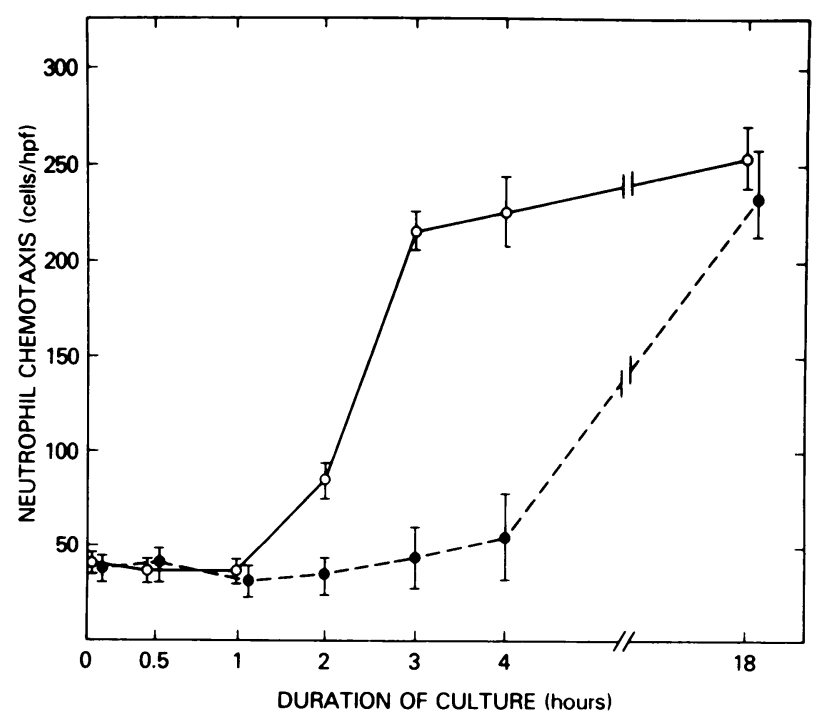

FIGURE 2 Neutrophil chemotactic activity in supernates of control alveolar macrophages (- - ) or macrophages stimulated for various periods of time in vitro by opsonized $S$. albus $(\mathrm{O}-\mathrm{O})$. Neutrophil chemotaxis expressed as the number of cells per high power field (hpf) reaching the lower surface of a micropore filter. The data represent the mean \pm SEM of three separate experiments. 
phages contained levels of chemotactic activity comparable to that of supernates derived from stimulated macrophages. The production of chemotactic factor by control macrophages cultured for $18 \mathrm{~h}$ can likely be ascribed to the stimulating effect of attachment and spreading on the culture dish; unstimulated macrophages kept in suspension for $18 \mathrm{~h}$ (by tumbling in plastic tubes) produced no chemotactic factor. Macrophage adherence to a plate was not critical for generation of the chemotactic factor, because stimulated macrophages kept in suspension by tumbling in plastic tubes produced AMCF (data not shown).

The ability of particulates to stimulate the macrophages to produce the chemotactic factor seemed to be associated with either phagocytosis of the particulate or attachment of the macrophages to the particulate. For example, the macrophages phagocytized S. albus and zymosan and they attached to the Sepharose-4B, all of which stimulated the macrophages to produce the chemotactic factor. In comparison, macrophages neither phagocytized nor attached to untreated ORBC and supernates of the macrophages plus ORBC cultures did not contain any chemotactic activity (Fig. 3).

Ability of immune complexes to stimulate macrophages to release the chemotactic factor. Whereas untreated ORBC did not stimulate human alveolar macrophages to release the chemotactic factor, IgGcoated ORBC (particulate immune complexes) and BSA-IgG anti-BSA (soluble immune complexes) induced the macrophages to generate quantities of chemotactic factor comparable to that induced by op-

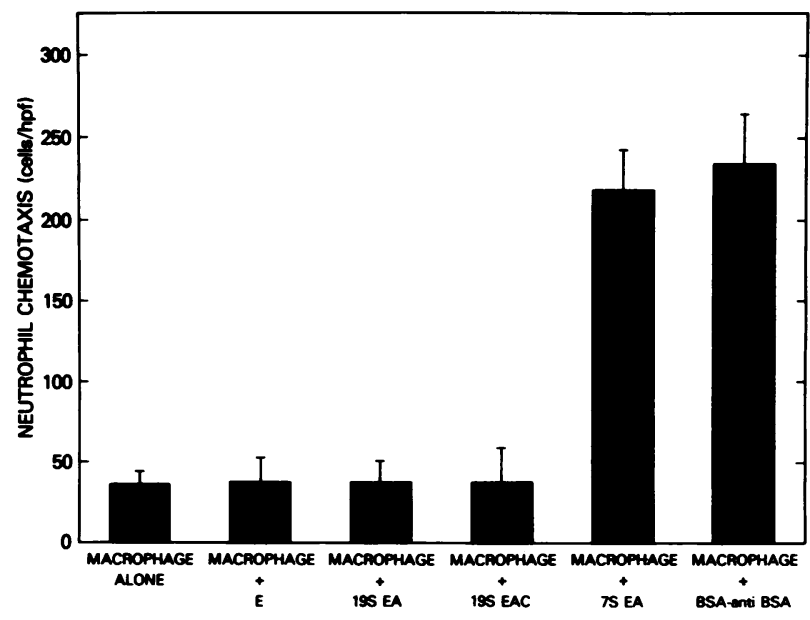

FIGURE 3 Neutrophil chemotactic activity in supernates of control alveolar macrophages compared with macrophages incubated in vitro for $3 \mathrm{~h}$ with ORBC (E), ORBC coated with IgM (19S EA), SRBC coated with IgM and complement (19S EAC), ORBC coated with IgG (7S EA), or soluble BSAIgG anti-BSA. Neutrophil chemotaxis is expressed as the number of cells per high power field (hpf) reaching the lower surface of a micropore filter. The data represent the mean \pm SEM of three separate experiments. sonized zymosan particles (Fig. 3). The ability of immune complexes to stimulate the macrophages in this fashion seemed to be specific for IgG; macrophages exposed to IgM-coated ORBC did not generate the chemotactic factor. This specificity for IgG was probably associated with the ability of the IgG-immune complexes to interact with the macrophages as neither untreated ORBC nor IgM-coated ORBC formed rosettes with the macrophages. In contrast, the IgGcoated ORBC formed rosettes with, and were phagocytized by, the macrophages. However, the stimulation of the macrophages by the IgG-ORBC complexes was not simply due to the fact that the IgG-ORBC complexes were capable of interacting with the macrophages, since SRBC coated with IgM and complement could adhere to the macrophages but were not ingested and did not trigger chemotactic factor release. In comparison, IgG-coated SRBC were ingested by the macrophages and they were effective as IgG-coated ORBC in stimulating the release of the chemotactic factor (data not shown).

General considerations of the AMCF. The supernates of the stimulated macrophages fulfilled the accepted criteria for being a chemotactic factor (20). When the supernate was present on both sides of the filter (i.e., without a gradient), it increased the random migration of the neutrophils in proportion to its concentration (data not shown). However, when the supernate was present only on the stimulus side of the filter (thus creating a gradient), the numbers of neutrophils migrating through the filter at each concentration level were greater than that due to random migration alone.

Comparison of the relative activity of the chemotactic factor for neutrophils, monocytes, and eosinophils. To evaluate the relative chemotactic activity of the AMCF for neutrophils vs. monocytes, serial dilutions of the chemotactic factor were compared in their ability to attract neutrophils or monocytes to migrate across the micropore filter. The chemotactic factor possessed considerably more chemotactic activity for neutrophils than monocytes (Fig. 4). To place this finding in perspective, the chemotactic activity of $6 \mu$ l of the alveolar macrophage supernate was comparable to $90 \%$ of the activity of the endotoxin-activated human serum for neutrophils and $8 \%$ of the activity of the activated human serum for monocytes.

The preferential chemotactic activity of AMCF for neutrophils vs. monocytes could not be explained by a selective deactivation of mononuclear cells by the factor (Table I). In fact, AMCF was more potent in deactivating neutrophils than monocytes. The deactivation of neutrophils by the AMCF was not selective for this factor, since these cells also exhibited decreased chemotactic migration to $\mathrm{N}$-formyl-Met-Leu-Phe and endotoxin-activated serum. 


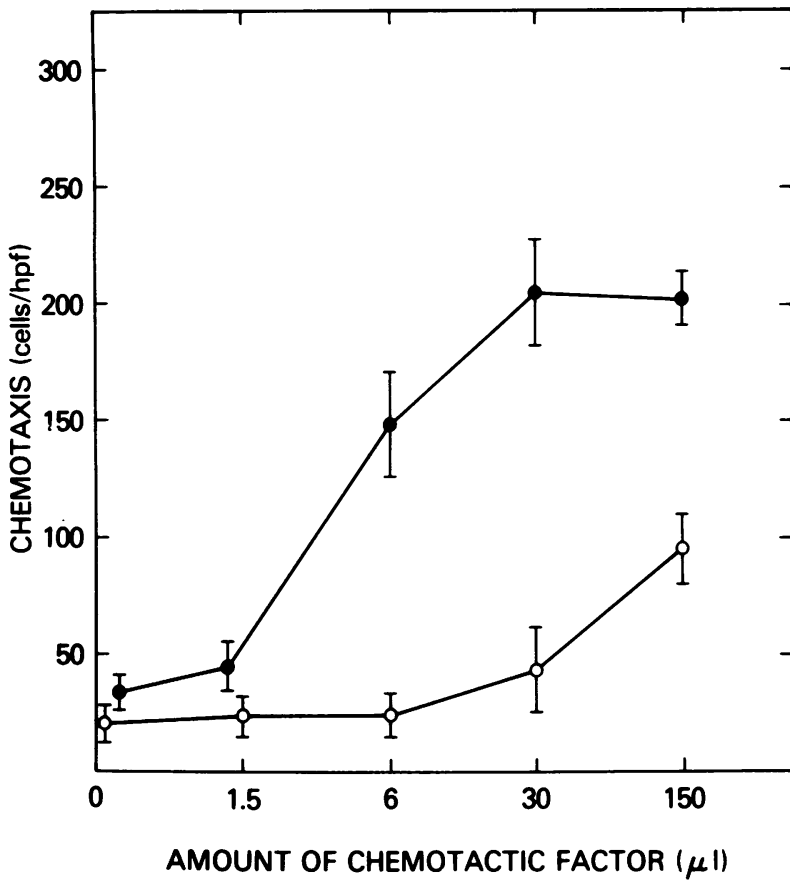

FIGURE 4 Comparison of the relative target cell specificity of the AMCF. Various amounts of the chemotactic factor (generated by macrophages exposed to Sepharose-4B) were made to a total volume of $150 \mu \mathrm{l}$ and placed in the lower well of the chemotaxis chamber, and peripheral blood mononuclear cells $(80 \%$ lymphocytes $-20 \%$ monocytes $)(O-O)$ or neutrophils $(-O)$ were placed in the upper chamber. The results are expressed as the number of cells per high power field (hpf) reaching the lower surface of a micropore filter. The data represent the mean $\pm S E M$ of three separate experiments.

To compare the relative activity of the chemotactic factor for neutrophils vs. eosinophils, PMN cell suspensions containing both of these cell types were obtained from peripheral blood of three individuals with allergic rhinitis. For these studies, both the micropore filter assay and a chemotaxis-under-agarose assay were used. Both methods of analysis demonstrated that the chemotactic factor possessed more activity for neutrophils than eosinophils (data not shown).

Partial characterization of the chemotactic factor. Greater than $80 \%$ of the chemotactic activity of the macrophage supernates was stable to heating at $56^{\circ} \mathrm{C}$ for $30 \mathrm{~min}$ and $100^{\circ} \mathrm{C}$ for $30 \mathrm{~min}$, at $\mathrm{pH} 1.0,3.5,9.0$, and 12.0 for $60 \mathrm{~min}$, and after exposure to papain (10 $\left.\mu \mathrm{g} / \mathrm{ml}, 30 \mathrm{~min}, 37^{\circ} \mathrm{C}\right)$, trypsin $\left(10 \mu \mathrm{g} / \mathrm{ml}, 30 \mathrm{~min}, 37^{\circ} \mathrm{C}\right)$, chymotrypsin $\left(10 \mu \mathrm{g} / \mathrm{ml}, 30 \mathrm{~min}, 37^{\circ} \mathrm{C}\right)$, collagenase $\left(10 \mu \mathrm{g} / \mathrm{ml}, 30 \mathrm{~min}, 37^{\circ} \mathrm{C}\right)$, and elastase $(10 \mu \mathrm{g} / \mathrm{ml}, 30 \mathrm{~min}$, $\left.37^{\circ} \mathrm{C}\right)$ (Table II). No chemotactic activity was generated following exposure of supernates of unstimulated macrophages (which did not contain the chemotactic factor) to identical concentrations of each of the enzymes described above. However, preincubation of the chemo-
TABLE I

Capacity of the AMCF to Deactivate Neutrophils and Mononuclear Cells to Subsequent Chemotactic Stimulation

\begin{tabular}{lllrr}
\hline & \multicolumn{4}{c}{ Chemotactic stimuli } \\
\cline { 2 - 5 } $\begin{array}{c}\text { Type of cells prein- } \\
\text { cubated with various } \\
\text { amounts of AMCF }\end{array}$ & $\begin{array}{l}\text { Media } \\
\text { alone* }\end{array}$ & AMCF & FMLPt & AS\$ \\
\hline & & \multicolumn{2}{c}{$150 \mu l$} \\
Neutrophils & & & & \\
$+0 \mu$ l AMCF" & $28 \pi$ & 198 & 215 & 205 \\
$+6 \mu$ l AMCF & 20 & 56 & 49 & 66 \\
$+30 \mu$ l AMCF & 21 & 31 & 42 & 48 \\
Mononuclear cells & & & & \\
$+0 \mu$ l AMCF & 15 & 68 & 55 & 180 \\
$+6 \mu$ l AMCF & 18 & 56 & 52 & 166 \\
$+30 \mu$ l AMCF & 12 & 52 & 49 & 124 \\
\hline
\end{tabular}

* RPMI-1640 (150 $\mu \mathrm{l})$.

$\ddagger N$-formyl-Met-Leu-Phe $(50 \mathrm{nM} ; 150 \mu \mathrm{l})$.

$\$$ Endotoxin-activated human serum $(5 \%, 150 \mu \mathrm{l})$.

"Neutrophils and mononuclear cells were incubated with varying amounts of the AMCF before their subsequent stimulation with various chemotactic factors.

I Neutrophils or mononuclear cells reaching the lower surface of the nucleopore filters in response to various chemotactic factors.

tactic factor with a serum-derived chemotactic factor inhibitor resulted in $90 \%$ decrease in the chemotactic activity of the macrophage-produced factor.

TABLE II

Characteristics of the Human AMCF

\begin{tabular}{lr}
\hline \multicolumn{1}{c}{ Conditions } & $\begin{array}{c}\text { Percentage of } \\
\text { original activity* }\end{array}$ \\
\hline Chemotactic factor & 100 \\
+ Heating $\left(30 \mathrm{~min}, 56^{\circ} \mathrm{C}\right)$ & 105 \\
+ Heating $\left(30 \mathrm{~min}, 100^{\circ} \mathrm{C}\right)$ & 95 \\
+ pH $1.0(60 \mathrm{~min})$ & 98 \\
+ pH $3.5(60 \mathrm{~min})$ & 105 \\
+ pH $9.0(60 \mathrm{~min})$ & 97 \\
+ pH $12.0(60 \mathrm{~min})$ & 99 \\
+ Chemotactic factor inhibitor $\downarrow$ & 10 \\
+ Trypsin $\left(10 \mu \mathrm{g} / \mathrm{ml}, 30 \mathrm{~min}, 37^{\circ} \mathrm{C}\right) \S$ & 94 \\
+ Chymotrypsin $\left(10 \mu \mathrm{g} / \mathrm{ml}, 30 \mathrm{~min}, 37^{\circ} \mathrm{C}\right) \S$ & 96 \\
+ Papain $\left(10 \mu \mathrm{g} / \mathrm{ml}, 30 \mathrm{~min}, 37^{\circ} \mathrm{C}\right) \S$ & 92 \\
+ Collagenase $\left(10 \mu \mathrm{g} / \mathrm{ml}, 30 \mathrm{~min}, 37^{\circ} \mathrm{C}\right) \S$ & 98 \\
+ Elastase $\left(10 \mu \mathrm{g} / \mathrm{ml}, 30 \mathrm{~min}, 37^{\circ} \mathrm{C}\right) \S$ & 93 \\
Media alone & 0
\end{tabular}

* The percentage of original activity was estimated by determining the dilution of the chemotactic factor which resulted in a 50\% maximal migration of neutrophils in the chemotaxis assay.

\& Chemotactic factor inhibitor was prepared as described in Methods.

$\$$ After incubation with the chemotactic factor. The enzyme was inactivated by heating at $100^{\circ} \mathrm{C}$ for $15 \mathrm{~min}$. 


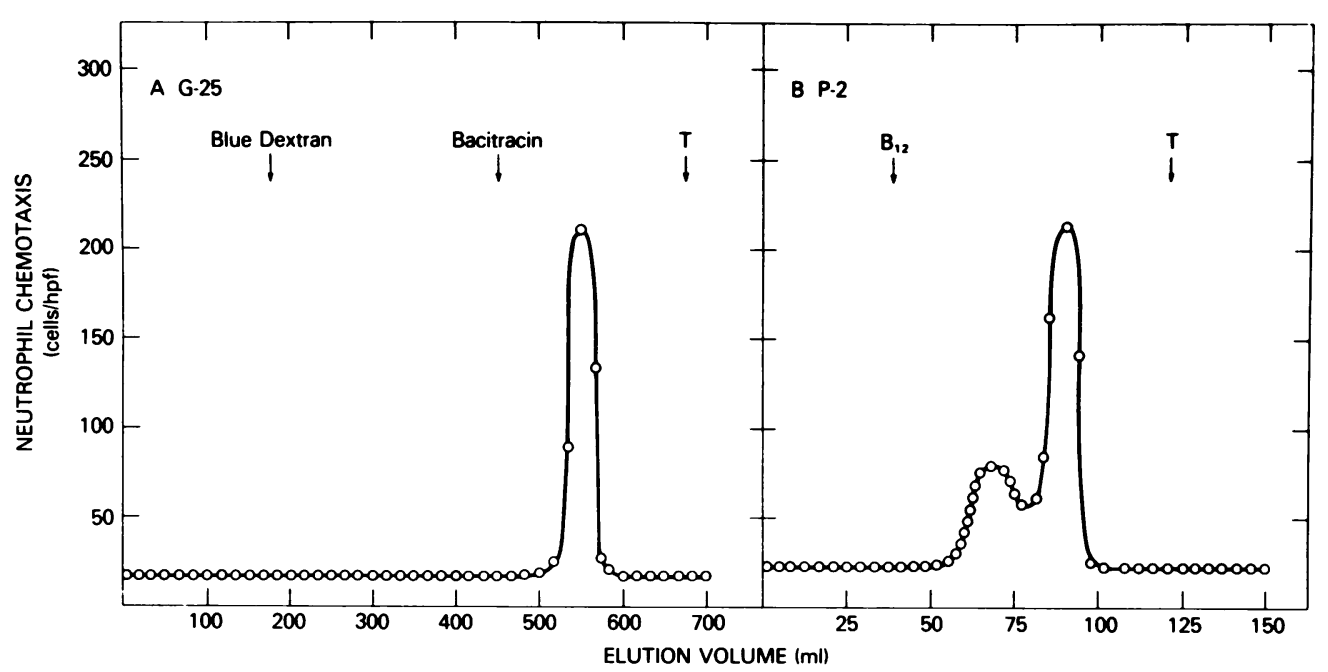

FIGURE 5 Molecular weight estimation of the human AMCF. The chemotactic factor was generated by alveolar macrophages exposed to Sepharose-4B particles. (A) Sephadex G-25 column chromatography; (B) Bio-Gel P-2 column chromatography. Both columns were eluted at $4^{\circ} \mathrm{C}$ with $40 \mathrm{mM}$ PBS, pH 7.4. Neutrophil chemotaxis is expressed as the number of cells per high power field (hpf) reaching the lower surface of the micropore filter. Molecular weight markers include: blue dextran $\left(2 \times 10^{6}\right)$, bacitracin $(1,450)$, vitamin $\mathrm{B}_{12}(1,350)$, and $\left[{ }^{3} \mathrm{H}\right]$ thymidine (T) (242).

Sephadex G-25 and Bio-Gel P-2 fractionation of the macrophage chemotactic factor revealed that the major portion (>75\%) of the chemotactic activity of AMCF eluted with an apparent molecular weight of 400-600 (Fig. 5). Isoelectric focusing of the AMCF (400-600 mol wt) revealed two major peaks of activity at $\mathrm{pI}$, 7.6 and 5.2 (Fig. 6).

At least a portion of AMCF appeared to be composed of lipid. Extraction into organic solvents revealed that $75 \%$ of AMCF activity was removed from the macrophage supernates after extraction with ethyl acetate at $\mathrm{pH} 3.5,80 \%$ with ethyl acetate at pH $7.4,25 \%$ with ethyl acetate at $\mathrm{pH} 12,60 \%$ with ether at $\mathrm{pH} 7.4$, and 45\% with hexane at pH 7.4 (Table III). The activity that was removed from the macrophage supernates was recovered from the respective organic solvents. The chemotactic factor present in supernates of unstimulated macrophages at $18 \mathrm{~h}$ of culture exhibited similar solvent partition characteristics to the chemotactic factor which was present in supernates of stimulated macrophages at $3 \mathrm{~h}$ of culture (data not shown).

Because at least a portion of AMCF appeared to be composed of lipid, the macrophage supernates were further evaluated for the presence of hydroxylderivatives of HETE (products of the lipoxygenase pathway of arachidonic acid which are known to be chemotactic for neutrophils) (24). GC-MS analysis of the macrophage supernates did not detect HETE at the $0.4 \mathrm{ng} / \mathrm{ml}$ level. Since a 1:10 dilution of the macrophage supernates has neutrophil chemotactic activity, and because prior studies by Goetzl et al. (33) have shown that HETE does not demonstrate chemotactic activity for neutrophils at a concentration of less than $1 \mu \mathrm{g} / \mathrm{ml}$, HETE could not possibly account for the majority of the chemotactic activity of AMCF in our studies. In fact,

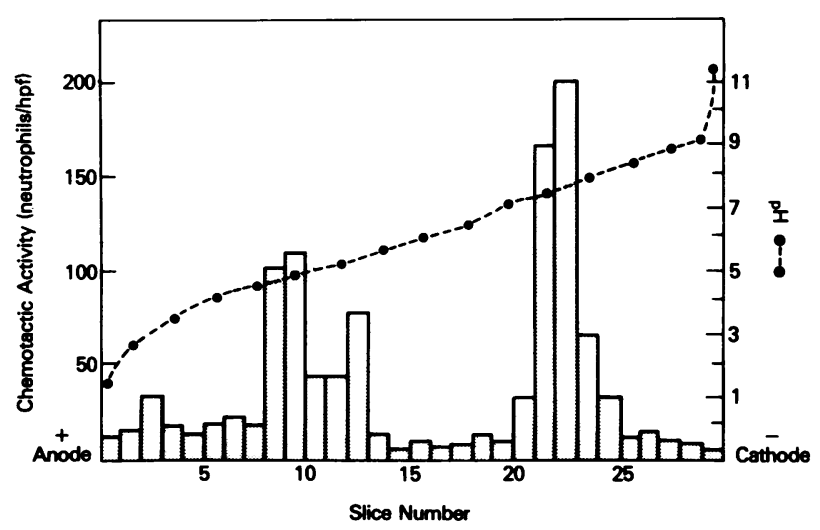

FIgURE 6 Isoelectric focusing of the AMCF in a horizontal bed of granulated gel with a pH gradient of 2.5-9. The pH gradient was established using a composite of ampholytes at a final concentration of $2 \%$ (wt/wt) in the gel slurry. AMCF, partially purified by prior gel filtration, was added to the granulated gel bed ( $3 \% \mathrm{vol} / \mathrm{vol})$ before application of the electrofocusing current $\left(25 \mathrm{~W}, 5^{\circ} \mathrm{C}, 16 \mathrm{~h}\right)$. The gel was then collected as 75-mm strips proceeding from anode to cathode and each gel fraction was eluted with $3 \mathrm{ml}$ of $0.85 \% \mathrm{NaCl}-40 \mathrm{mM}$ phosphate, pH 7.4. The eluate from the gel strips was then assayed for neutrophil chemotactic activity. Gel fractions from control experiments that did not contain AMCF demonstrated that the granulated gel-ampholyte focusing bed itself did not contain measurable neutrophil chemotactic activity. 
TABLE III

Extraction of the AMCF into Organic Solvents

\begin{tabular}{llc}
\hline \multicolumn{1}{c}{ Solvent } & Condition & $\begin{array}{c}\text { Percentage of } \\
\text { original activity } \\
\text { extracted }\end{array}$ \\
\hline AMCF alone & - & 100 \\
Extracted into ethyl acetate & pH 3.5 & 75 \\
& pH 7.4 & 80 \\
Extracted into ether & pH 12.0 & 25 \\
Extracted into hexane & pH 7.4 & 60 \\
\hline
\end{tabular}

* The percentage of original activity extracted was estimated by determining the dilution of the chemotactic factor that resulted in a 50\% maximal migration of neutrophils in the chemotaxis assay.

if HETE is present, it is at a concentration $2.5 \times 10^{-4}$ less than the minimum $1 \mu \mathrm{g} / \mathrm{ml}$ level suggested by Goetzl et al.

Effect of the macrophage-derived chemotactic factor on neutrophils. In addition to inducing neutrophils to follow a path of directed migration, the macrophage chemotactic factor also stimulated human neutrophils to release lysozyme and lactoferrin but not $\beta$-glucuronidase or LDH (Fig. 7). Additional studies demonstrated that the lysozyme and lactoferrin found in the cultures of macrophage supernates plus neutrophils were derived from the neutrophils and not the macrophages. Direct evaluation of the supernates of stimulated macrophages demonstrated that: $(a)$ although small amounts of lysozyme were present, it contributed to $<5 \%$ of that found in the cultures of macrophage supernates plus neutrophils; and $(b)$ no lactoferrin was present.

\section{DISCUSSION}

A number of acute and chronic lung disorders are characterized by the accumulation of neutrophils in the alveolar structures (5-14). The present study suggests that the alveolar macrophage plays a central role in modulating neutrophil migration to the lung by generating and releasing a low molecular weight chemotactic factor that preferentially attracts neutrophils. The release of AMCF can be triggered by microorganisms, noninfectious particulates, and immune complexes, each of which are models for lung disorders associated with neutrophil accumulation in the lower respiratory tract (5-14). Because this chemotactic factor is generated rapidly following interaction of the macrophage with each of these pathogenic agents, its release may account for the accumulation of neutrophils in the lung soon after a pathologic insult. In addition, the fact that this chemotactic factor is not released spontaneously from unstimulated alveolar macro- phages is consistent with the observation that neutrophils are rarely found in the lungs of normal individuals.

Characteristics of the chemotactic factor. Several lines of evidence demonstrated that the macrophagederived chemotactic factor was not related to any serum-derived chemotactic factor (34-37). First, it could be produced in the absence of serum or any serum component. Second, it was not inactivated by an anti-C5a antibody, demonstrating that it was not C5a, the major complement-derived chemotactic factor (data not shown) (37). Third, the small molecular weight of the chemotactic factor distinguished it from the serum-derived chemotactic factors that are generated as a result of activation of the complement system, Hageman factor, or the kinin-generating system (34-37). These observations also suggest that AMCF was not derived from the action of macrophage-produced proteases on serum components in a manner analogous to PMN protease digestion of IgG (38) or C5 (39).

In addition, it is unlikely that the macrophagederived chemotactic factor was related to the presence

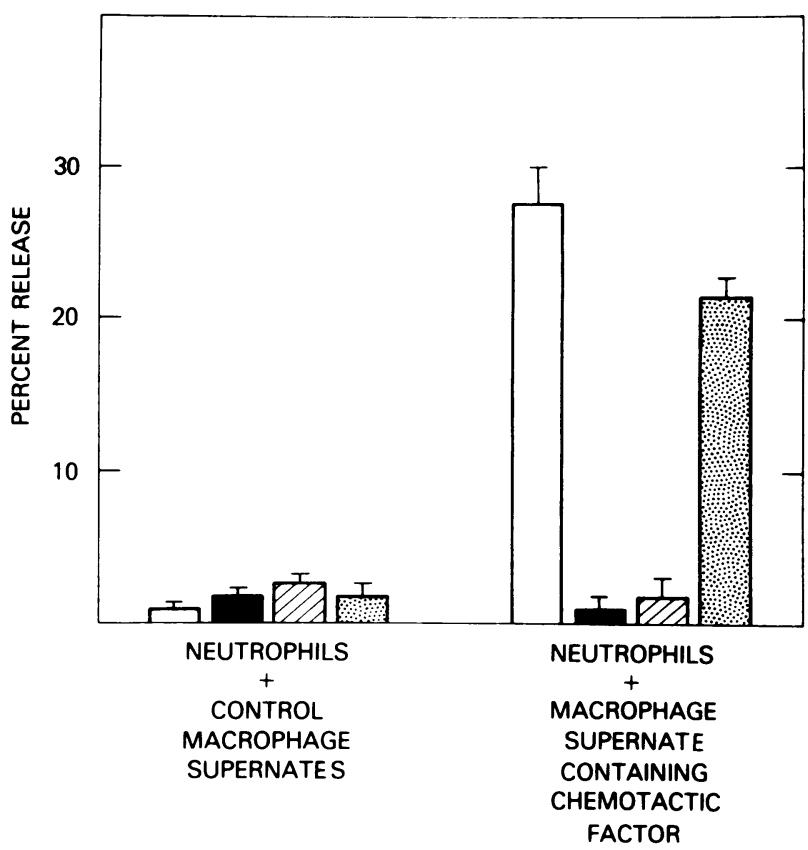

Figure 7 Release of lysozyme ( $\square$ ), $\beta$-glucuronidase $\mathbf{\square}$, LDH $(\mathbb{Q})$, and lactoferrin (W) from neutrophils exposed for $2 \mathrm{~h}$ to supernates from unstimulated macrophages ("control") and supernates from macrophages stimulated with Sepharose4B. The supernates from the macrophages stimulated with Sepharose-4B contained the chemotactic factor, whereas the supernates from the unstimulated macrophages did not. Assays for the release of lysozyme, $\beta$-glucuronidase, and LDH were performed with $10^{7}$ neutrophils; "100\% release," that amount of lysozyme, $\beta$-glucuronidase, and LDH present in $10^{7}$ neutrophils. The assays for the release of lactoferrin were performed with $5 \times 10^{7}$ neutrophils; "100\% release," that amount of lactoferrin present in $5 \times 10^{7}$ neutrophils. 
of chemotactic products of bacteria $(16,17)$, because cultures of the lavage fluid from all of the normal volunteers were sterile as were the macrophage cultures themselves.

Partial characterization of AMCF suggested that it was small (400-600 mol wt) and heterogeneous; two distinct peaks of chemotactic activity were obtained following isoelectric focusing (pI 7.5, 5.2). In addition, the partial solubility of the AMCF in various organic solvents suggests that at least $50-80 \%$ of the chemotactic activity may be derived from lipid factors.

Although AMCF appears to be at least partially lipid in nature, it is distinct from HETE (a previously described lipid chemotactic factor for neutrophils) (24). GC-MS analysis of supernates of stimulated macrophages demonstrated that, if HETE was present in these supernates, it was at a concentration so low that it could not possibly have accounted for the neutrophil chemotactic activity of AMCF. Although these studies demonstrate that the majority of the chemotactic activity of AMCF is not due to HETE, it is possible that, under certain conditions, HETE may be obtained from alveolar macrophages, at least in some species. In this regard, Valone et al. (40), utilizing techniques that were different from those used to isolate AMCF in the present study, demonstrated that rabbit alveolar macrophages are capable of producing HETE (40).

The activity of the AMCF was stable at both acid and alkaline $\mathrm{pH}$ and following exposure to temperatures up to $100^{\circ} \mathrm{C}$ for $30 \mathrm{~min}$. Like other chemotactic factors for neutrophils, the macrophage-derived chemotactic factor could be inactivated by the serum-derived inhibitor described by Berenberg and Ward (26), suggesting that physiologic mechanisms may exist in vivo to regulate macrophage induction of neutrophil traffic to the lung.

The chemotactic factor derived from human alveolar macrophages closely resembles the small molecular weight neutrophil chemotactic factors derived from alveolar macrophages of monkey (3) and guinea pigs (4), suggesting few, if any, species differences exist. It is not known, however, whether these AMCF are distinguishable from the small molecular weight chemotactic factors present in transfer factor preparations (41).

Evaluation of the specificity of AMCF demonstrated that it influenced the migration of several types of peripheral blood leukocytes including neutrophils, eosinophils, and mononuclear cells. However, its activity for neutrophils exceeded that of eosinophils and mononuclear cells. This is in contrast to the specificity of the small molecular weight peptide chemotactic factors derived from mast cells (ECF-A), which preferentially attracts eosinophils $(42,43)$. Additional studies demonstrated that the bulk of the AMCF was not ECF-A. The low molecular weight chemotactic peptides derived from mast cells are acidic peptides that elute from Dowex-1 columns (Dow Corning Corp., Midland, Mich.) at pH 3.2 to 2.3 (43). Isoelectric focusing of AMCF demonstrated no chemotactic activity at these isoelectric points. A low molecular weight (300-400) chemotactic factor with preferential activity for eosinophilic polymorphonuclear leukocytes has also been isolated from extracts to bronchogenic carcinomas and a renal cell carcinoma metastatic to the lung (44). This factor differed from ECF-A derived from mast cells in that it eluted from Dowex-1 columns at pH 5.5 to 4.5 rather than 3.2 to 2.2 . Isoelectric focusing of the AMCF revealed a similar peak of chemotactic activity with a pI of 5.2; however, the partial solubility of the AMCF in lipid solvents demonstrates that at least a portion of the chemotactic activity derived from macrophages is not identical to the factors derived from lung tumors. In addition, it is clear that the cell of origin of all of the chemotactic activity present in AMCF differs from that of the factors present in the lung tumors. Finally, the more basic chemotactic molecules (pI 7.6) that are present in the AMCF are clearly different from the ECF derived from mast cells or lung tumors, both in terms of their charge and solubility in organic solvents.

The AMCF stimulated both random migration as well as directed migration (chemotaxis) of neutrophils, thus fulfilling the accepted criteria for being a chemotactic factor. However, the macrophage supernates not only attracted neutrophils but, in addition, also stimulated neutrophils to release lysozyme and lactoferrin. This is of interest, because it suggests that the stimulated alveolar macrophage not only can amplify the inflammatory response by recruiting blood leukocytes but also by stimulating those leukocytes to discharge at least some of their stored products.

Stimuli for generation and release of the chemotactic factor. A wide variety of seemingly unrelated stimuli are capable of triggering the release of the chemotactic factor from alveolar macrophages. Each of these stimuli has a common effect on macrophages in that they all interact with the macrophage membrane. In the case of S. albus, zymosan particles, Sepharose4B, and extended attachment to a plastic surface, the nature of this interaction is not clear. In contrast, the ability of immune complexes to trigger chemotactic factor release seems to be mediated specifically through the IgG-Fc receptor, because IgM EAC do not stimulate chemotactic factor release, even though they attach to the macrophage membrane via the macrophage $\mathrm{C} 3 \mathrm{~b}$ receptor. Interestingly, however, $\mathrm{C} 3 \mathrm{~b}$ on particulates does appear to increase the release of the chemotactic factor; serum-treated S. albus, zymosan, and Sepharose-4B all cause chemotactic factor release beyond that due to the particles themselves.

Independent of the mechanisms by which these stimuli exert their influence on the macrophage to pro- 
duce the chemotactic factor, it is important that these stimuli are representative of a spectrum of pathogenic agents that cause neutrophil accumulation in the lower respiratory tract. Thus, the macrophage seems to have multiple means by which it can interact with pathogenic agents: first, it can phagocytize the agent; second, it can destroy it by secreting a variety of enzymes and other toxic materials; and third, it can enlist the aid of polymorphonuclear leukocytes by secreting a low molecular weight chemotactic factor.

\section{REFERENCES}

1. Green, G. M. 1970. The J. Burns Amberson Lecture: in defense of the lung. Am. Rev. Respir. Dis. 102: 691-703.

2. Goldstein, E., W. Lippert, and K. Warshauer. 1974. Pulmonary alveolar macrophage. Defender against bacterial infection of the lung. J. Clin. Invest. 54: 519-528.

3. Kazmierowski, J. A., J. I. Gallin, and H. Y. Reynolds. 1977. Mechanism for the inflammatory response in primate lungs. Demonstration and partial characterization of an alveolar macrophage-derived chemotactic factor with preferential activity for polymorphonuclear leukocytes. J. Clin. Invest. 59: 273-281.

4. Hunninghake, G. W., J. I. Gallin, and A. S. Fauci. 1978. Immunological reactivity of the lung. The in vivo and in vitro generation of a neutrophil chemotactic factor by alveolar macrophages. Am. Rev. Respir. Dis. 117: 15-23.

5. Wood, W. B. 1941. Studies on the mechanisms of recovery in pneumococcal pneumonia. I. The action of type specific antibody upon the pulmonary lesion of experimental pneumonia. J. Exp. Med. 73: 201-222.

6. Wood, W. B. 1951. Studies on the cellular immunology of acute bacterial infections. Harvey Lect. 47: 72-98.

7. Reynolds, H. Y., J. D. Fulmer, J. A. Kazmierowski, W. C. Roberts, M. M. Frank, and R. G. Crystal. 1977. Analysis of cellular protein content of bronchoalveolar lavage fluid from patients with idiopathic pulmonary fibrosis and chronic hypersensitivity pneumonitis. J. Clin. Invest. 59: 165-175.

8. Crystal, R. G., J. D. Fulmer, W. C. Roberts, M. L. Moss, B. R. Line, and H. Y. Reynolds. 1976. Idiopathic pulmonary fibrosis: clinical, histologic, radiographic, physiologic, scintigraphic, cytologic, and biochemical aspects. Ann. Intern. Med. 88: 769-788.

9. Fulmer, J. D., and R. G. Crystal. 1979. Interstitial lung disease. In Current Pneumonology. D. H. Simmons, editor. Houghton Mifflin Company, Boston. 1-65.

10. Hunninghake, G. W., J. A. Kelman, J. E. Gadek, N. A. Elson, J. D. Fulmer, and R. G. Crystal. 1978. Comparison of inflammatory and immune effector cell populations in lavage fluid and lung biopsies of patients with pulmonary fibrosis. Am. Rev. Respir. Dis. 117: 68. (Abstr.)

11. Dreisin, R. B., M. I. Schwarz, A. N. Theofilopoulos, and R. E. Stanford. 1978. Circulating immune complexes in the idiopathic interstitial pneumonias. N. Engl.J. Med. 98: 353-357.

12. Gadek, J. E., G. W. Hunninghake, T. A. Lawley, J. A. Kelman, J. D. Fulmer, and R. G. Crystal. 1978. Role of immune complexes in amplifying the alveolitis of idiopathic pulmonary fibrosis. Clin. Res. 26: 446A. (Abstr.)

13. Weinberger, S. E., J. A. Kelman, N. A. Elson, R. C. Young, H. Y. Reynolds, J. D. Fulmer, and R. G. Crystal. 1978. Bronchoalveolar lavage in interstitial lung disease. Ann. Intern. Med. 89: 459-466.

14. Hunninghake, G. W., J. E. Gadek, O. Kawanami, and V. J.
Ferrans, and R. G. Crystal. 1979. Inflammatory and immune processes in the human lung in health and disease. Evaluation by bronchoalveolar lavage. Am. J. Pathol. 97: 149-206.

15. Böyum, A. 1968. Isolation of mononuclear cells and granulocytes from human blood. Scand. J. Clin. Invest. 21 (Suppl. 97): 77-89.

16. Ward, P. A., I. H. Lepow, and L. J. Newman. 1968. Bacterial factors chemotactic for polymophonuclear leukocytes. Am. J. Pathol. 52: 725-736.

17. Schiffman, E., H. Showell, B. Corcoran, E. Smith, P. A. Ward, T. Tempel, and E. L. Becker. 1974. Isolation and characterization of the bacterial chemotactic factor. Fed. Proc. 33: 631. (Abstr.)

18. Fine, D. P., S. R. Manney, D. G. Colley, J. S. Sergent, and R. M. Des Pres. 1972. C3 shunt activation in human serum chelated with EGTA. J. Immunol. 109: 807-809.

19. Hunninghake, G. W., J. E. Gadek, R. C. Young, O. Kawanami, V. J. Ferrans, and R. G. Crystal. 1980. Maintenance of granuloma formation in pulmonary sarcoidosis by T-lymphocytes within the lung. N. Engl.J. Med. 301: 594-597.

20. Zigmond, S. H., and J. G. Hirsch. 1973. Leukocyte locomotion and chemotaxis. New methods for evaluation and demonstration of a cell-derived chemotactic factor. $J$. Exp. Med. 137: 387-410.

21. Nelsen, R. D., V. D. Fiegel, and R. L. Simmons. 1976. Chemotaxis of human polymorphonuclear neutrophils under agarose: morphologic changes associated with the chemotactic response. J. Immunol. 117: 1676-1683.

22. Gallin, J. I., R. A. Clark, and M. M. Frank. 1975. Kinetic analysis of chemotactic factor generation in human serum via activation of the classical and alternate complement pathways. Clin. Immunol. Immunopathol. 3: 334-346.

23. Righetti, P. G., and J. W. Drysdale. 1976. Preparative isoelectric focusing in granulated gels. In Laboratory Techniques in Biochemistry and Molecular Biology. T. S. Word and E. Work, editors. North-Holland Publishing Company, Amsterdam. 5: Part II.

24. Goetzl, E. J., J. M. Woods, and R. R. Gorman. 1977. Stimulation of human eosinophil and neutrophil polymorphonuclear leukocyte chemotaxis and random migration by 12-L-hydroxy-5,8,10,14-eicosatetraenoic acid. J. Clin. Invest. 59: 179-183.

25. Hamberg, M., and B. Samuelsson. 1974. Prostaglandin endoperoxides. Novel transformation of arachidonic acid in human platelets. Proc. Natl. Acad. Sci. U. S. A. 71: 3400-3404.

26. Berenberg, J. L., and P. A. Ward. 1973. Chemotactic factor inhibitor in normal human serum. J. Clin. Invest. 52: $1200-1206$.

27. Wright, D. G., and S. E. Malawista. 1972. The mobilization and extracellular release of granular enzymes from human leukocytes during phagocytosis. J. Cell Biol. 53: 788-797.

28. Goldstein, I. M., S. T. Hoffstein, and G. Weissman. 1975. Mechanisms of lysosomal enzyme release from human polymorphonuclear leukocytes: effects of phorbol myristate acetate. J. Cell Biol. 66: 647-652.

29. Becker, E. L., H. J. Showell, P. M. Henson, and L. S. Hsu. 1974. The ability of chemotactic factors to induce lysosomal enzyme release. J. Immunol. 112: 2047-2054.

30. Shugar, D. 1952. The measurement of lysozyme activity and the ultraviolet inactivation of lysozyme. Biochim. Biophys. Acta. 8: 302-309.

31. Fishman, W. H., B. Springer, and R. Brunetti. 1948. Application of an improved glucuronidase assay method to the 
study of human blood $\beta$-glucuronidase. J. Biol. Chem. 173: 449-456.

32. Masson, P. L., J. F. Heremans, and E. Schonne. 1969. Lactoferrin, an iron binding protein in neutrophilic leukocytes. J. Exp. Med. 130: 643-658.

33. Reeves, W. J., and M. F. Grace. 1963. An improved procedure for the preparation of crystalline lactic dehydrogenase from hog heart. J. Biol. Chem. 238: 3853-3858.

34. Ward, P. A., G. G. Cochrane, and J. H. Muller-Eberhard. 1965. The role of serum complement in chemotaxis of leukocytes in vitro. J. Exp. Med. 122: 327-346.

35. Kaplan, A. P., E. J. Goetzl, and K. F. Austen. 1973. The fibrinolytic pathway of human plasma. II. Generation of chemotactic activity by activation of plasminogen proactivator. J. Clin. Invest. 52: 2591-2597.

36. Kaplan, A. P., A. B. Kay, and K. F. Austen. 1972. A prealbumin activator of chemotactic activity for human neutrophils by the conversion of human prekallikrein to kallekrein. J. Exp. Med. 135: 81-97.

37. Fernandez, H. N., P. M. Henson, A. Otani, and T. E. Hugli. 1978. Chemotactic response to human C3a and C5a anaphylatoxins. Evaluation of $\mathrm{C} 3 \mathrm{a}$ and C5a leukotaxis in vitro and under simulated in vivo conditions. $J$. Immunol. 120: 109-114.

38. Yoshinaga, M., M. Mayumi, S. Yamamato, and H.Y. Yahoski. 1970. Immunoglobulin $G$ as a possible pre- cursor of chemotactic factor. Nature (Lond.). 225: 1138-1140.

39. Ward, P. A., and J. H. Hill. 1969. C5 chemotactic fragment produced by an enzyme in lysosomal granules of neutrophils. J. Immunol. 104: 535-541.

40. Valone, F. H., M. Franklin, and E. J. Goetzl. 1979. Generation of a human polymorphonuclear leukocyte (PMN) chemotactic factor by the lipoxygenase pathway of alveolar macrophages (AM). Clin. Res. 47: 476A. (Abstr.)

41. Gallin, J. I., and C. H. Kirkpatrick. 1974. Chemotactic activity in dialyzable transfer factor. Proc. Natl. Acad. Sci. U. S. A. 71: 498-502.

42. Kay, A. B., D. J. Steckshulte, and K. F. Austen. 1971. An eosinophil leukocyte chemotactic factor of anaphylaxis. J. Exp. Med. 133: 602-619.

43. Austen, K. F., S. I. Wasserman, and E. J. Goetzl. 1976. Mast cell-derived mediators: structural and functional diversity and regulation and expression. In Molecular and Biological Aspects of Acute Allergic Reactions. S. G. O. Johansson, K. Strandberh, and B. Uvnäs, editors. Plenum Publishing Corp., New York. 293-301.

44. Goetzl, E. J., A. H. Tashjian, R. H. Rubin, and K. F. Austen. 1978. Production of a low molecular weight eosinophil polymorphonuclear leukocyte chemotactic factor by anaplastic squamous cell carcinomas of the human lung. J. Clin. Invest. 61: 770-780. 